\title{
Predictive immunological markers in oncology
}

\section{Dirk Jäger*, Inka Seil and Niels Halama}

Medical Oncology, National Center for Tumor Diseases, University Medical Center Heidelberg, Heidelberg, Germany

*Correspondence: dirk.jaeger@med.uni-heidelberg.de

Most treatment decisions in oncology are still based on histomorphological criteria, criteria that are incorporated in actual staging systems. With just a few exceptions (i.e., leukemias, some lymphomas, GIST, NSCLC, etc.) molecular and immunological characteristics of individual tumors do not contribute to this process. The basis for clinical considerations and treatment indications are clinical trials. In these clinical trials, a specific treatment is associated with a statistical outcome for the entire patient population treated in this trial. Not surprisingly, a subgroup of patients does not benefit from the administered treatment and no biomarker to identify these patient subpopulations have been found. So treatment recommendations are typically given as recommendations for all patients with comparable disease situations. As an example, we treat patients with adjuvant chemotherapy knowing that a small minority, far less than $20 \%$ of all treated patients, benefits from such adjuvant treatments. The vast majority experiences only treatment related side effects. In parallel, this approach produces enormous costs for our health care system. In advanced disease situations, treatments leading to objective response rates of $30 \%$ and higher are considered to be effective treatments. Still, the majority of patients does not benefit and experiences treatment related side effects compromising their quality of life.

How to change this situation? In oncology, most systemic treatments consist of chemotherapy as single agent or combination treatment. We have not really understood why such treatments are effective only in some patients and while other patients progress under the same treatment. The era of gene expression profiling has not convincingly contributed to a better understanding of the individual tumor biology or reproducible molecular profiles with predictive value. With some exception for breast cancer, the characterization of "treatment responsive" versus "treatment resistant" tumors is not possible. The great hope of the oncology community is now that genome profiling and sequencing will give us more valuable insights into misregulated pathways driving tumor growth and metastases and a subsequent personalized approach to specifically target these alterations with novel drugs (Stratton, 2011).

It becomes more and more accepted that the fate of an individual tumor patient not only depends on the molecular characteristics of the tumor, the prognosis is also strongly influenced by tumor-host immune interactions. This has convincingly been shown for colon cancer and non-small cell lung cancer by Fridman and Galon (Zhang et al., 2003; Dieu-Nosjean et al., 2008), renal cancer and many other tumor entities. In those studies, investigators counted the number of infiltrating immune cells in primary tumors and demonstrated, that patients with high $\mathrm{T}$ cell density have a significant better prognosis than patients with low $\mathrm{T}$ cell density in the primary tumor. In colon cancer, $\mathrm{T}$ cell infiltrates in the primary tumor represent the strongest prognostic parameter compared to the currently used stage-defining parameters like tumor size, depth of infiltration, and nodal status (Galon et al., 2006). However, such immunological parameters are not routinely used in clinical practice yet. Why is this? Part of the reason is the difficulty to standardize such immunological diagnostic assessments. The pathologist is used to judge cell density on the basis of semi-quantitative scaling systems, the assessment of an exact immune cell density in an individual patient means to manually count cells of interest in different predefined regions of tissue. This is very time consuming and almost impossible for large sections, and there is a strong intra- and inter-observer variation.

To integrate immunological assessments into the clinical diagnostic routine, we need automated systems analyzing predefined tumor regions with sophisticated image analysis algorithms, dealing with all the challenges of cell shape diversity, cell conglomerates, etc. In addition to that, prog- nostic markers are useful for the judgment of an individual patients risk, but they do not help in our decision if a given treatment is going to increase an individual patient's survival. Therefore we desperately need markers that help to select for treatments, allowing to predict whether an individual patient is likely to benefit from a given treatment or dismiss treatments that are unlikely to be effective. With very few exceptions, such biomarkers have not been identified for the majority of tumor diseases (Benvenuti et al., 2007). We recently discovered the correlation of $\mathrm{T}$ cell infiltrates at the invasive margin of liver metastases of colorectal cancer patients with response to chemotherapy, progression free survival (PFS), and overall survival (OS; Halama et al., 2011). Patients with an intense T cell infiltrate at the invasive margin of liver metastases had very high response rates to conventional chemotherapy, a significant better PFS and OS than patients with relative low $\mathrm{T}$ cell densities. Interestingly, the cut off values defining $\mathrm{T}$ cell dense versus $\mathrm{T}$ cell low tumors are very similar to the numbers published by Galon et al. (2006) in primary colon cancers defining prognostically favorable versus unfavorable tumors. Infiltrate density heterogeneity is comparable to the situation in primary colon cancer (Halama et al., 2010) and T cell infiltrates are very heterogenic at the invasive margin of liver metastases. Therefore, larger tissue areas need to be analyzed to get reliable results for individual patients. Using a computational image analysis system we developed an automated platform allowing high throughput analysis of large tissue sections. Sophisticated algorithms based on morphological and spectral information identified immune cell densities in predefined tissue regions recognizing and addressing the challenges of non-uniformly shaped cells, different cell size, clustering, etc. Our system allows us now to analyze large tissue areas in patient samples, respecting the high heterogeneity of immune cell infiltrates in tumors. Analyzing just small tissue areas 
(tissue microarrays have $\sim 0.3 \mathrm{~mm}^{2}$ ), there is a strong bias, making interpretation of the data impossible for individual patients and leading to large patient cohorts to be analyzed to produce robust data. For an individual patient, larger tissue areas should be evaluated. Depending on the analyzed cell type, at least $3 \mathrm{~mm}^{2}$ is suitable to produce data that are of prognostic or predictive value for a single patient.

We could confirm our findings of the predictive significance of immune cell infiltrates at the invasive margin of colon cancer liver metastases in two independent patient cohorts undergoing chemotherapy and we just started a prospective clinical trial in metastatic colorectal cancer patients where we assess cellular immune responses at the tumor site before and under chemotherapy to better understand how chemotherapy modulates cellular immune responses and how chemotherapy impacts on the immunological micromilieu.

A provocative hypothesis could question, what the main mechanism of chemotherapy in advanced colorectal cancer might be: direct tumor cell killing or modulation of the immunological microenvironment? The latter mechanism then allowing cellular immune responses to invade and attack tumor cells.

Chemotherapy could potentially suppress inhibitory immune cell functions, facilitating tumor-specific T cells to invade and attack. This aspect is supported by the immunosurveillance theory developed by R. Schreiber and others (Dunn et al., 2002, 2004; Smyth et al., 2006). Additionally to that, chemotherapy induced cell death leads to activation of effector immune cells, the recognition of new antigens and a broad activation of the immune system, initially described as immunogenic cell death (Zitvogel et al., 2008a,b, 2011). To better understand the complex interplay of immune cell subsets in tumors, at the invasive margin and systemically, we need to monitor subpopulations like dendritic cells, macrophages, Th1 T cells, cytotoxic $\mathrm{T}$ cells, and natural killer cells which are thought to have anti-tumor effects and cancer-associated macrophages, myeloid derived suppressor cells, neutrophils, Th2 and Th17 T cells, and FOXP3-positive regulatory $\mathrm{T}$ cells with tumor promoting properties (Pages et al., 2009; Zitvogel et al., 2011).
Until now, we still treat patients with colorectal cancer according to their clinical stage which is purely based on tumor infiltration depth in the colon, presence or absence of lymph node metastases and distant metastases. Immunological parameters that help to define the prognosis in colorectal cancer (Pages et al., 2005; Galon et al., 2006) are still not applied in the clinic. Especially for adjuvant treatment, there is great clinical need for biological/immunological markers that help to identify patients likely or unlikely to benefit from chemotherapy. Our data from the metastatic disease situation suggest that immune cell dense patients are patients more likely to benefit from chemotherapy. Data for the adjuvant situation points into a similar direction but has not been analyzed systematically (Morris et al., 2008). Whether there is also a more complex differentiation necessary for colorectal cancer, remains to be seen. Up to now, the two main groups are patients with dense immune cell infiltrates and good prognosis versus patients with low immune cell infiltrates and poor prognosis. What should we do with the patients that have low T cell density at the tumor site that have a poor prognosis and are unlikely to benefit from chemotherapy? Is it possible to induce cellular immune responses in such patients and convert them from poor prognosis to good prognosis patients? Or define such immune cell infiltrates simply a more favorable tumor biology? To address this very important question, cellular immune responses in colon cancer patients need to be characterized carefully including detailed analysis of the immunological micromilieu in $T$ cell rich versus $T$ cell low patients, as well as the antigen specificity of such infiltrating $\mathrm{T}$ cells and the molecular profile - including the mutational profile - of immune cell dense versus immune cell low tumors. Until now it is still unknown what the targets of prognostic relevant $\mathrm{T}$ cell responses in colon cancer are. In the past we tried to identify or select antigens that are more or less abundantly and specifically expressed by tumor cells. Such antigens have been used in the past to induce or enhance cellular immune responses in patients. We might have missed the relevant antigens that could very well be mutated antigens. For malignant melanoma, these mutated antigens seem to form the largest group of antigens that are detected by $\mathrm{T}$ cells (Lennerz et al.,
2005). Robert Schreiber and his colleagues have shown in mouse sarcoma models that spontaneous $\mathrm{T}$ cell responses leading to tumor rejection or at least equilibrium state of immunosurveillance are directed against mutated antigens encoded by genes that have no obvious role in the respective tumor biology, most likely representing passenger mutations. If this is similar to the situation in humans, it could very well be that we need to analyze the spectrum of tumor mutations individually, test which of them are recognized by the individual host and use such target antigens for individual immunotherapeutical intervention.

There is great need to take this in consideration and incorporate immunological characterization of individual tumor diseases into the clinical routine. Knowing about the individual tumor biology and individual tumor immunology, we hopefully can design more intelligent and for the individual patient more effective treatment strategies. To realize this, we need to invest a lot more resources into diagnostic procedures, but such resources will be worth investing in as they definitely will allow to avoid ineffective, but expensive treatments.

\section{REFERENCES}

Benvenuti, S., Sartore-Bianchi, A., Di Nicolantonio, F., Zanon, C., Moroni, M., Veronese, S., Siena, S., and Bardelli, A. (2007). Oncogenic activation of the RAS/ RAF signaling pathway impairs the response of metastatic colorectal cancers to anti-epidermal growth factor receptor antibody therapies. Cancer Res. 67, 2643-2648.

Dieu-Nosjean, M. C., Antoine, M., Danel, C., Heudes, D. Wislez, M., Poulot, V., Rabbe, N., Laurans, L., Tartour, E., de Chaisemartin, L., Lebecque, S., Fridman, W. H., and Cadranel, J. (2008). Long-term survival for patients with non-small-cell lung cancer with intratumoral lymphoid structures. J. Clin. Oncol. 26, 4410-4417.

Dunn, G. P., Bruce, A. T., Ikeda, H., Old, L. J., and Schreiber, R. D. (2002). Cancer immunoediting: from immunosurveillance to tumor escape. Nat. Immunol. 3, 991-998.

Dunn, G. P., Old, L. J., and Schreiber, R. D. (2004). The immunobiology of cancer immunosurveillance and immunoediting. Immunity 21, 137-148.

Galon, J., Costes, A., Sanchez-Cabo, F., Kirilovsky, A., Mlecnik, B., Lagorce-Pages, C., Tosolini, M., Camus, M., Berger, A., Wind, P., Zinzindohoue, F., Bruneval, P., Cugnenc, P. H., Trajanoski, Z., Fridman, W. H., and Pages, F. (2006). Type, density, and location of immune cells within human colorectal tumors predict clinical outcome. Science 313, 1960-1964.

Halama, N., Michel, S., Kloor, M., Zoernig, I., Benner A., Spille, A., Pommerencke, T., von Knebel, D. M., Folprecht, G., Luber, B., Feyen, N., Martens, U. M., Beckhove, P., Gnjatic, S., Schirmacher, P., Herpel, E., Weitz, J., Grabe, N., and Jaeger, D. (2011). Localization 
and density of immune cells in the invasive margin of human colorectal cancer liver metastases are prognostic for response to chemotherapy. Cancer Res. 71, 5670-5677.

Halama, N., Zoernig, I., Spille, A., Michel, S., Kloor, M., Grauling-Halama, S., Westphal, K., Schirmacher, P., Jager, D., and Grabe, N. (2010). Quantification of prognostic immune cell markers in colorectal cancer using whole slide imaging tumor maps. Anal. Quant. Cytol. Histol. 32, 333-340.

Lennerz, V., Fatho, M., Gentilini, C., Frye, R. A., Lifke, A., Ferel, D., Wolfel, C., Huber, C., and Wolfel, T. (2005).The response of autologous $\mathrm{T}$ cells to a human melanoma is dominated by mutated neoantigens. Proc. Natl. Acad. Sci. U.S.A. 102, 16013-16018.

Morris, M., Platell, C., and Iacopetta, B. (2008). Tumorinfiltrating lymphocytes and perforation in colon cancer predict positive response to 5-fluorouracil chemotherapy. Clin. Cancer Res. 14, 1413-1417.

Pages, F., Berger, A., Camus, M., Sanchez-Cabo, F., Costes, A., Molidor, R., Mlecnik, B., Kirilovsky, A., Nilsson, M., Damotte, D., Meatchi, T., Bruneval, P., Cugnenc, P. H., Trajanoski, Z., Fridman, W. H., and Galon, J.
(2005). Effector memory T cells, early metastasis, and survival in colorectal cancer. N. Engl. J. Med. 353, 2654-2666.

Pages, F., Kirilovsky, A., Mlecnik, B., Asslaber, M., Tosolini, M., Bindea, G., Lagorce, C., Wind, P., Marliot, F., Bruneval, P., Zatloukal, K., Trajanoski, Z., Berger, A., Fridman, W. H., and Galon, J. (2009). In situ cytotoxic and memory $\mathrm{T}$ cells predict outcome in patients with early-stage colorectal cancer. J. Clin. Oncol. 27, 5944-5951.

Smyth, M. J., Dunn, G. P., and Schreiber, R. D. (2006). Cancer immunosurveillance and immunoediting: the roles of immunity in suppressing tumor development and shaping tumor immunogenicity. Adv. Immunol. 90, 1-50.

Stratton, M. R. (2011). Exploring the genomes of cancer cells: progress and promise. Science 331, 1553-1558.

Zhang, L., Conejo-Garcia, J. R., Katsaros, D., Gimotty, P. A., Massobrio, M., Regnani, G., Makrigiannakis, A., Gray, H., Schlienger, K., Liebman, M. N., Rubin, S. C., and Coukos, G. (2003). Intratumoral T cells, recurrence, and survival in epithelial ovarian cancer. N. Engl. J. Med. 348, 203-213.
Zitvogel, L., Apetoh, L., Ghiringhelli, F., Andre, F., Tesniere, A., and Kroemer, G. (2008a). The anticancer immune response: indispensable for therapeutic success? J. Clin. Invest. 118, 1991-2001.

Zitvogel, L., Apetoh, L., Ghiringhelli, F., and Kroemer, G. (2008b). Immunological aspects of cancer chemotherapy. Nat. Rev. Immunol. 8, 59-73.

Zitvogel, L., Kepp, O., and Kroemer, G. (2011). Immune parameters affecting the efficacy of chemotherapeutic regimens. Nat. Rev. Clin. Oncol. 8, 151-160.

Received: 02 December 2011; accepted: 15 December2011; published online: 06 January 2012.

Citation: Jäger D, Seil I and Halama N (2012) Predictive immunological markers in oncology. Front. Immun. 2:86. doi: 10.3389/fimmu.2011.00086

This article was submitted to Frontiers in Tumor Immunity, a specialty of Frontiers in Immunology.

Copyright $(5) 2012$ Jäger, Seil and Halama. This is an openaccess article distributed under the terms of the Creative Commons Attribution Non Commercial License, which permits non-commercial use, distribution, and reproduction in other forums, provided the original authors and source are credited. 